\title{
More Facts About the Flettner Rotor Ship
}

\section{The Constructional, Operating and Theoretical Data for This Remarkable and Novel Sailing Ship, Some Illustrations of Which Were Presented in Our Last Issue}

By H. O. Herzog

Consulting Engineer, Berlin, Germany

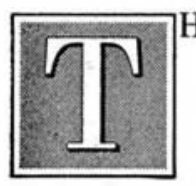

E veil of secrecy which has surrounded the details of the new rotor sailing ship invented by Herr Anton Flettner and so much discussed in the newspapers and technical periodicals of the entire world was lifted recently by the inventor himself in an address before the German Society of Naval Architects. In this address Herr Flettner summarized the experimental work which led up to his invention, described in detail the operation of his ship, illustrating the whole with motion pictures, and laid his ideas in full before the engineering world.

Herr Flettner is an engineer who has already made a name for himself by the so-called Flettner rudder, now used extensively in Germany and abroad. In the present investigation, however, his primary object was to increase the efficiency of the sailing ship. He was of the opinion, in the beginning, that the application of modern aerodynamics could not fail to produce improvements in the sailing vessel. Here, however, he encountered disappointment.

Sails made of thin metal proved superior in the matter of effective momentum but were too topheavy and too difficult to manage to be of practical use. After testing all the possibilities in this direction Herr Flettner embarked, ultimately, on an entirely new line of research. His starting point was the so-called Magnus effect, named after the famous Berlin scientist Magnus who proposed as far back as 1853 a theory, now rejected by many, in explanation of the well-known side deflection of an artillery projectile rotating around its axis.

\section{Effects Due to Air Friction}

If an object, for example, a cylinder is placed vertically in a current of air it will be encircled by the latter equally on both sides. If this cylinder is given a rotary motion it is discovered that the air current deviates strongly to the one side on which the circumference of the cylinder is moving with the current. This is explained by the increased air friction on the one side and diminished air friction on the other side due to the rotation of the cylinder. Another way of stating this theory is to say that

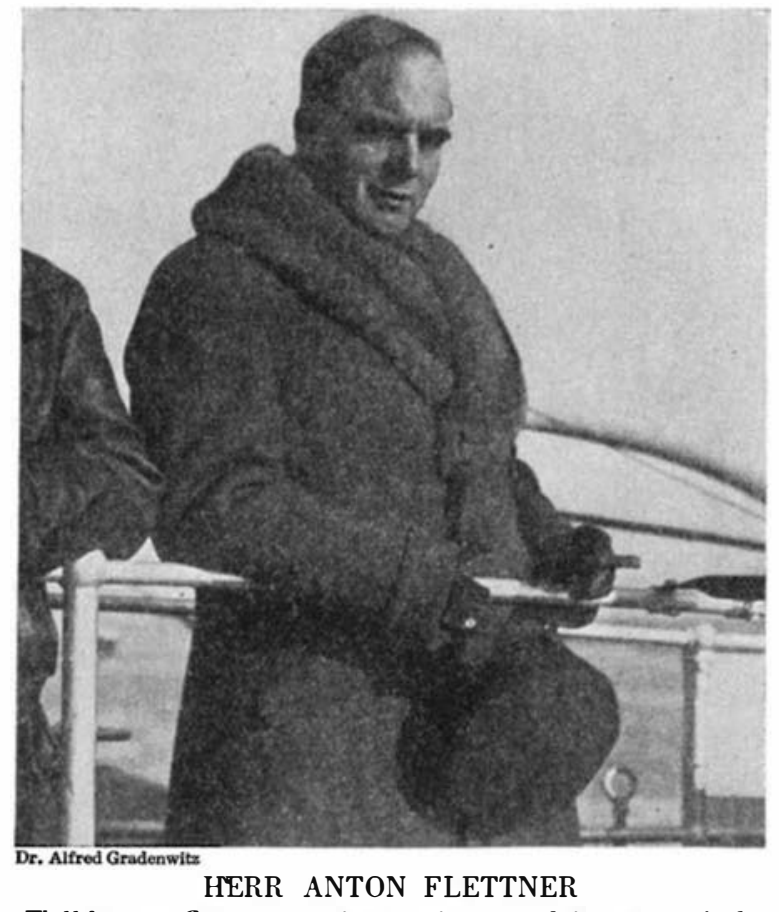

W'ell-known German marine engineer and inventor of the new method of ship propulsion by wind

because of friction a film of air rotates with the cylinder. On the side where the rotation of the cylinder is counterwise to the current of air this film of air produces congestion and consequent pressure. On the other side it produces suction.

A force thus results acting on the cylinder at right angles to the direction of the current of air. This fact was well known but was considered of no practical value. Mr. Flettner claims the merit of having discovered that the force thus produced can assume under certain circumstances, a considerable magnitude, by far surpassing the propelling power of ordinary wind pressure on the same cylinder or other object when the object is at rest.

These tests have revealed the fact that the force of suction on the one side of the cylinder when it is rotating is much larger than the force of pressure on the other side. The algebraic sum of these two - which sum is equal, of course, to the difference in air pressure against the cylinder on its two sides-is the force which serves to propel the ship equipped with Herr Flettner's rotating towers or "rotors."

The magnitude of this force varies with the ratio between the circumferential speed of the rotating cylinder and the velocity of the wind. When these speeds are equal this ratio is 1 and the propulsive force created by the Magnus effect is equal to the lateral wind pressure against the cylinder. As the speed of the cylinder increases, the propulsive force increases also until it reaches a maximum when the ratio of the two speeds is approximately 3.5 to 1 . At this maximum, the propulsive force caused by the Magnus effect is approximately ten times as great, Herr Flettner reports, as is the direct pressure of a wind of the same velocity against the stationary cylinder.

For example, in a wind having a velocity of thirty feet a second (about twenty miles an hour) and with a cylinder having a circumferential speed 3.5 times as great, or 105 feet a second, the propulsive force will be approximately ten times greater than the force against a sail having the same cross-section as the cylinder. It should be emphasized that the cylinder speed is the circumferential speed, not the speed of rotation.

\section{Inventor Could Not Obtain Support}

This astounding increase of wind pressure due to the rotation of the cylinders does seem to justify the enthusiasm acclaiming the Flettner invention as the discovery of a new power. So unexpected was the discovery and so fantastic did its practical application seem, that the inventor encountered a good deal of scepticism when trying to enlist help to carry on his work and to put it into practice. This was not mentioned, of course, in Herr Flettner's paper but it is an open secret that he found in the whole of Germany hardly anyone whom he could convince of the feasibility of his invention, much less someone to finance it. It was only with the help of Dutch capital that the inventor could complete his tests and proceed to practical trials.

It was for these trials that the ${ }^{*} 600$-ton brig Buckau was bought, her rigging removed and re-

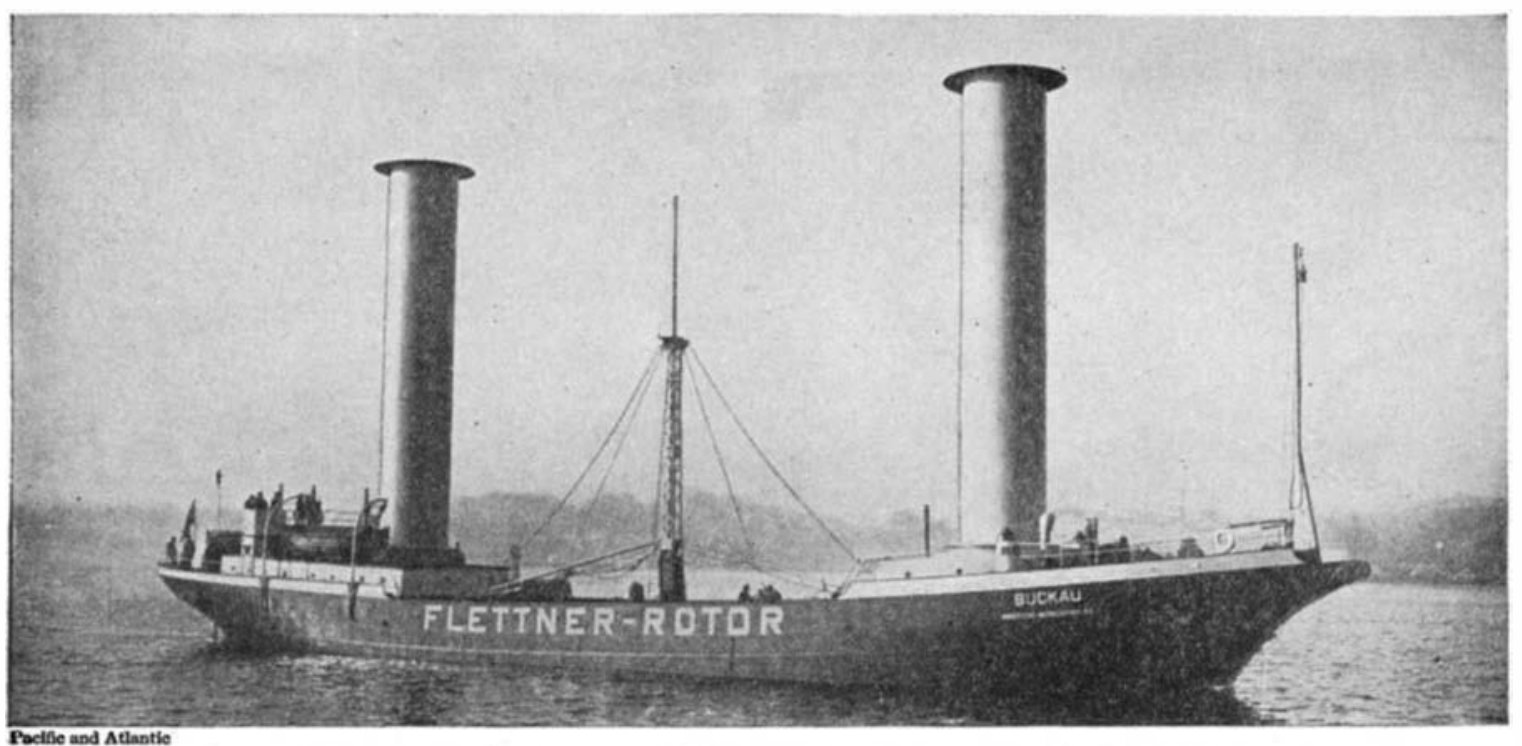

THIS IS THE TRIAL SHIP FITTED WITH FLETTNER ROTORS

The brig Buckau of 600 tons carries two revolving towers of sheet-steel, each 52 feet high and 10 feet in diameter. The rims at the tops of the towers are important

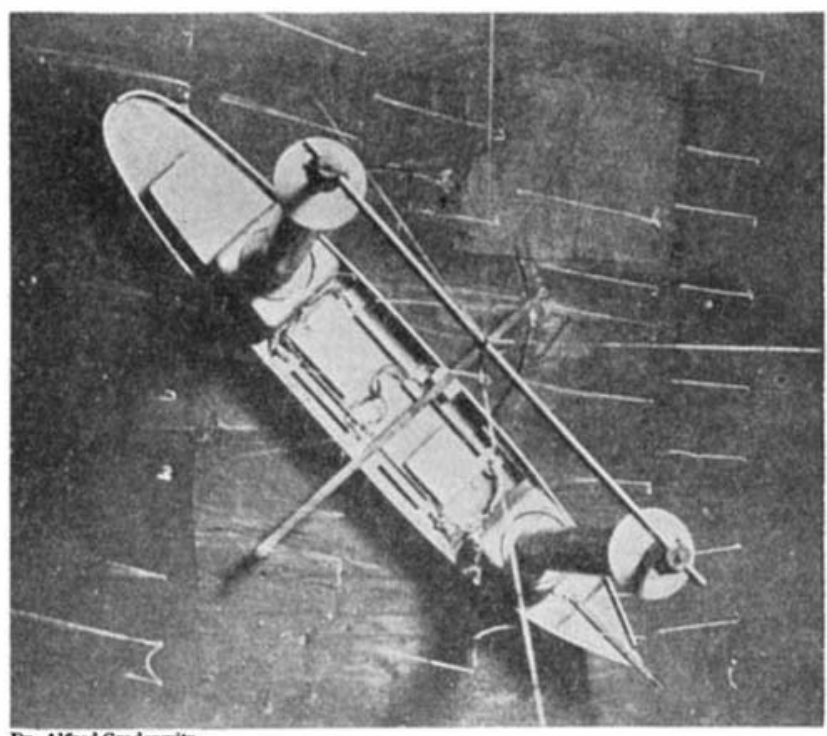

SMALL MODEL USED FOR FIRST TESTS

This small model, only a few inches long, had pasteboard towers rotated by clockwork. Note the threads showing wind direction 


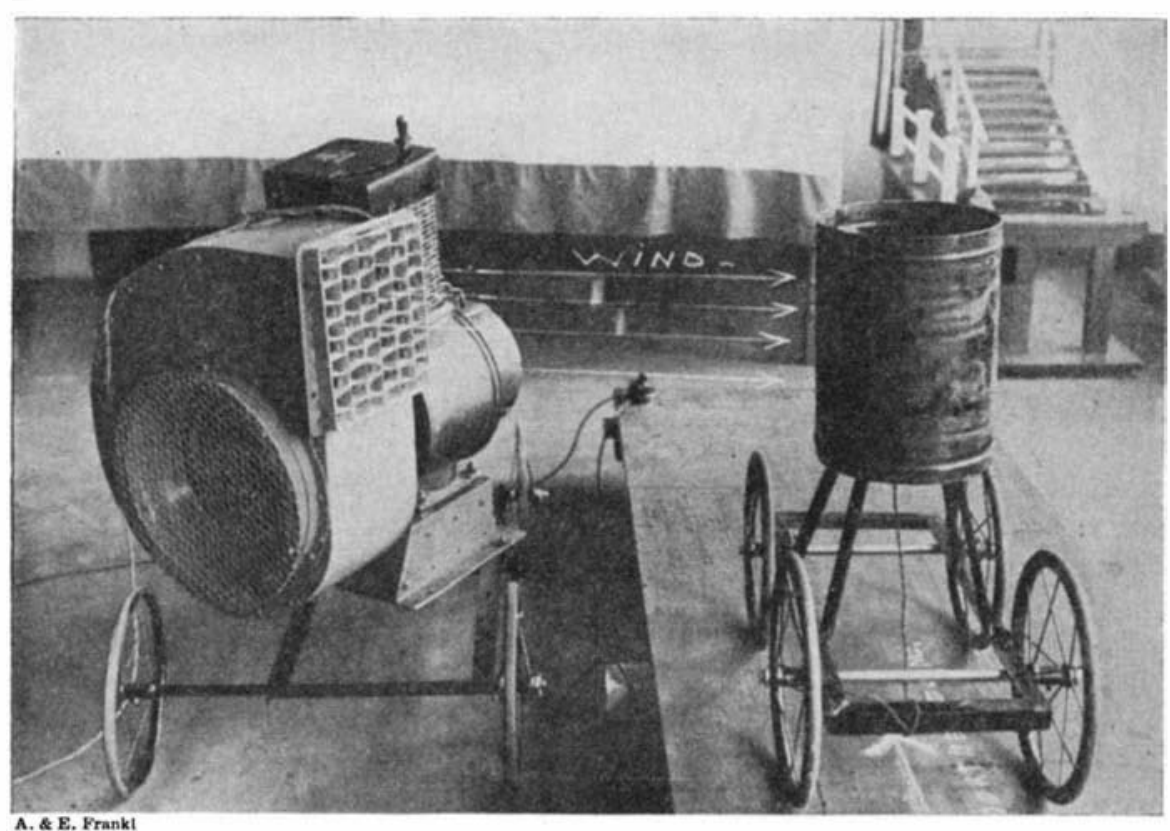

AN EASY WAY TO SHOW THE MAGNUS EFFECT The metal cylinder mounted on the small carriage is rotated by an electric motor. The
carriage then moves across the wind

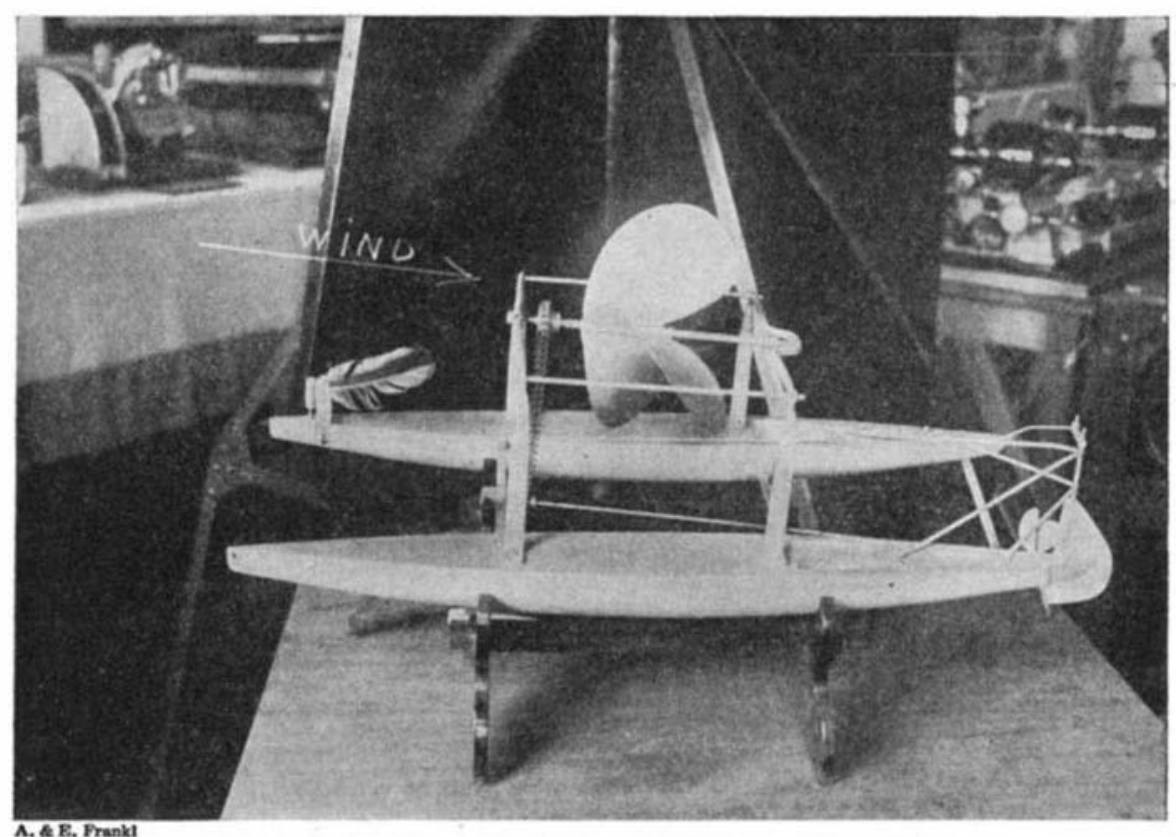

AN OLDER SUGGESTION FOR A WIND-POWER SHIP

This model, built by J. Smit in Holland in 1890, was intended to operate by a windmill which was connected, in turn, to the screw placed by the Flettner equipment. This consists, first: of all, of two round, tapering standards, mounted in the place of the masts. These act as supports for the rotors. The rotors are vertical cylinders, 52 feet high and 10 feet in diameter. These cylinders have a sliding bearing at the base and another one at about two-thirds of the cylinder height above the deck. The cylinders are made of steel sheets, 4/100 inch thick, strengthened internally by steel webs. Inside the cylinders are two inspection platforms, over the bearings. These are accessible through manholes. The inventor further pointed to the possibility of increasing the propelling power of the vessel by making the cylinders of corrugated sheets.

The cylinders carry at their tops a rim projecting about fourteen inches. This rim has a special function. It preserves the pressure and suction zones extending lengthwise on the respective sides of the cylinder and prevents these zones being penetrated by outside air from above.

The projected area of this whole super-structure is about 940 square feet. The propelling power which the two cylinders produce under wind pressure if rotated at a ratio of $\frac{\mathrm{u}}{\mathrm{v}}=3,5$ (in which " $\mathrm{u}$ " is the circumferential speed of the cylinders and "v" is the velocity of the wind) equals that of two sails with a combined area about ten times as large, that is of 9,400 square feet. The inventor stated that on the trial runs with the Buckau a speed of nine miles an hour has been achieved in a wind of medium force. Exact data were not given. It was stated merely that the cylinders rotated at a speed of 100 revolutions per minute. This corresponds to a circumferential speed of 53 feet per second and for the above relation of $\frac{\mathbf{u}}{\mathrm{v}}=3,5$ the velocity of the wind would be only 15 feet per second, which makes the stated ship speed look highly improbable. However, more data will doubtless be available soon.

\section{Revolving Power from Diesel Engine}

Power for the rotors is provided by two directcurrent, shunt-wound electric motors, each of 11 kilowatt rating. Both motors are reversible and operate at 220 volts and 750 revolutions per minute. Power is supplied by a two-cylinder Diesel engine rated at 45 horsepower. This engine may be directly connected, it is stated, to a screw, when it serves to propel the ship in the usual fashion, although at a slow speed. Storage batteries may be used to take the current from the generating system when not needed, and supply it to the rotor motors later on when it is needed.

A special study has been made, the inventor said, of the important problem of stability under heavy wind pressure. The weight of the whole superstructure is now 20 tons, the cylinders alone weighing three tons each. The complete former rigging of the vessel weighed 35 tons. Curves were shown comparing the wind pressure on a close-reefed rig and on Flettner's rotor stacks, both when at rest and in motion. According to these curves the wind pressure on the two stacks combined when at rest is only about half that on the corresponding closereefed sailing rig. Herr Flettner explains that circular stacks of such large diameter produce less wind pressure than thinner objects like ropes, spars, yards and masts, totaling an equal projected area.

If the cylinders rotate, the wind pressure increases in a steep curve. The peculiar fact has been found, however, that after reaching a force of about 5,000 kilograms per square meter (about seven pounds per square inch) at a velocity of 40 feet per second, the wind pressure does not increase further but remains almost stationary.

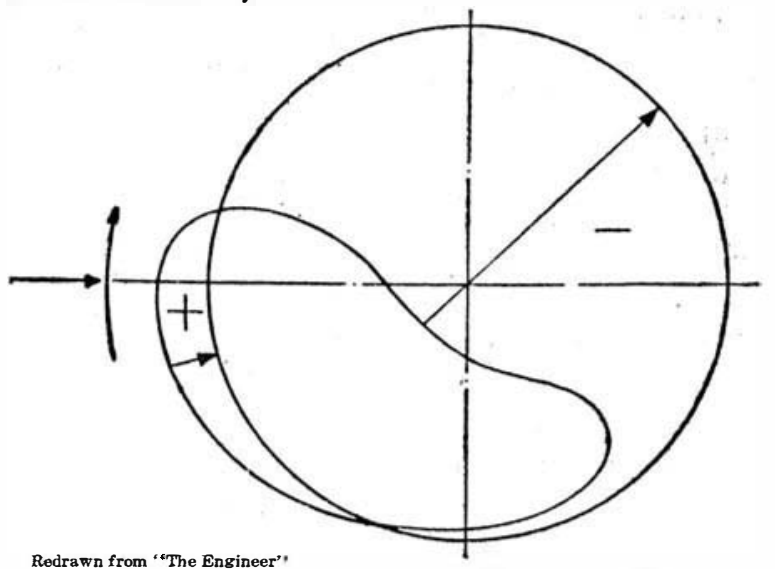

DIAGRAM OF THE MAGNUS EFFECT The wind and the rotation being as shown by the arrows
to the left, the excesses and the deficiencies of air presto the left, the excesses and the deficiencies of air presother arrows mark the resultant forces

Herr Flettner stated that by using light metal like duralumin for the superstructure, the weight of the equipment over deck can probably be reduced to one-half of its present weight. The question of stability is one, Herr Flettner said, which is completely under control, as the wind pressure on the stacks is a function of their revolving speed. Should the ship become too cranky in heavy storms all that is required is to reduce the rotation of the cylinders or to stop them entirely.
As a matter of fact the pictures presented to the audience showing the trial trips of Flettner's ship showed it riding on an even keel in rather a stiff breeze when all other sailing craft in the vicinity were noticeably heeled over. This may be due, however, to the fact that the force of wind pressure on the Flettner ship aets at a right angle to the direction of the wind, as has already been explained. A wind dead on the beam, therefore, has the same effect as a quarter wind in an ordinary sailing vessel. As the force of the wind pressure then acts in the direction of the longitudinal axis of the ship, there is no pressure at all on either side.

The navigation of the ship is simple. It is not steered with the rudder alone. The rotors are controlled from the bridge and take an important part in it. To turn the ship in the wind the front rotor is stopped and the rear one reversed. The whole ship can be reversed instantly by reversing the rotation. Deviation from the course can be corrected by adjusting the relative speed of rotation of the two cylinders. The practical limit for tacking was stated to be three and one-half points.

\section{What Will She Do in a Storm?}

There are, however, a number of obvious disadvantages. The rotating speed of the heavy and gigantic circular stacks surely has its limitations. Apart from the doubt of how these cylinders will behave in gales, with an enormous pressure thus created on their bearings, it is extremely uncertain that their circumferential speed can safely be kept three and one-half times as large as the velocity of wind in all kinds of weather.

It appears, therefore, that the ship cannot fully utilize strong winds. It is further handicapped in light weather on account of its comparatively low rigging. Another disadvantage seems to be that the wind pressure acts at right angles to the direction of the wind. In a course dead before the wind the propelling power would be almost nil. The ship would then have to tack or to run with cylinders at rest using their projected area as sails.

After-beam winds, in the case of the Flettner ship, produce the same effect as before-beam wind in ordinary craft. The most favorable wind is one dead on the beam. The quarter winds correspond with before-beam winds.

Further developments will show how these disadvantages, of which there are many more than sug. gest themselves at first sight, can be overcome and how fully they are counter-balanced by the merits of the invention. 